\title{
Analisis novel pudarnya pesona cleopatra karya Habiburrahman El- Shirazy ditinjau dari aspek sosiologi sastra
}

\author{
Ryan Hidayat ${ }^{1,}{ }^{*}$, Prima Pantau Putri Santosa ${ }^{2}$ \\ Program Studi Arsitektur, Fakultas Teknik Ilmu Komputer, Universitas Indraprasta PGRI \\ ${ }^{1}$ ryan.hidayat@ unindra.ac.id *; ${ }^{2}$ primapantauputrisantosa@gmail.com \\ *korespondensi penulis
}

\begin{tabular}{ll}
\hline Informasi artikel & \\
\hline Sejarah artikel: & \\
Diterima & $: 5$ Maret 2019 \\
Revisi & $: 9$ April 2019 \\
Dipublikasikan & $: 30$ April 2019 \\
\hline
\end{tabular}

Kata kunci:

Novel

Pudarnya pesona cleopatra

Sosiologi

Sastra

\begin{abstract}
ABSTRAK
Tujuan dari penelitian ini adalah untuk mendeskripsikan sejauh mana aspek sosiologi karya sastra dalam novel Pudarnya Pesona Cleopatra karya Habiburrahman El-shirazy. Metodologi dalam penelitian ini adalah metode deskriptif analisis isi, dengan menggambarkan aspek sosiologi sastra dalam Novel Pudarnya Pesona Cleopatra karya Habiburrahman El-shirazy. Hasil dan pembahasan data yang diperoleh dari Novel Pesona Pudarnya Cleopatra karya Habiburrahman El-shirazy yang terdiri dari 5I halaman. Novel dianalisis berdasarkan pada aspek sosiologi sastra, yang meliputi sosiologi suatu karya sastra, I) unsur sistem sosial: sistem politik sebanyak 0 poin, sistem kepercayaan I8 poin, sistem ekonomi 9 poin, dan sistem pendidikan sebanyak 6 poin, 2) sistem nilai sebanyak 20 poin dan sistem ide 6 poin, dan 3) budaya peralatan sebanyak 3 poin.

ABSTRACT

The purpose of the study are to assess described the extent to which aspects concerning the achievement of sociology of a literary work in the novels of pudarnya a charm cleopatra the work of habiburrahman el-shirazy .Planned in the methodology for in this research was a method of descriptive of an analysis of the contents of the , by portraying the aspect of sociology literature in the novels of pudarnya a charm cleopatra the work of habiburrahman el-shirazy .The results and of discussion to be addressed the data obtained from the of novels a charm pudarnya clepoatra the work of habiburrahman el-shirazy consisting of 5I in the picture to the . Of novels analyzed according on the aspects falling under sociology literature, which includes the sociology a literary work, I ) the element of a social system: a political system as many as 0 points, a system of belief I8 points, the economic system 9 points, and the system of education as many as 6 points , 2 ) value system as many as 20 points and a system of an idea 6 points, and 3 ) culture equipment as many as 3 points
\end{abstract}

\section{Key word:}

Novel

Pudarnya pesona cleopatra

sociology

Literature

Copyright (C) 2019 Universitas Ahmad Dahlan

\section{Pendahuluan}

Karya sastra merupakan suatu totalitas yang memiliki nilai seni yang dapat dinikmati oleh khalayak masyarakat. Karya sastra yang dapat dinikmati oleh para pembaca bisa berbentuk puisi, prosa, dan drama. Akan tetapi, berdasarkan sejarah perkembangan sastra dan minat pembaca di Indonesia semakin meningkat, prosa yang berbentuk novel-lah yang menjadi primadona sastra dari dulu hingga sekarang. Sebuah karya sastra khususnya novel yang bisa diterima oleh masyarakat tidaklah mudah. Seorang sastrawan atau pengarang haruslah mencurahkan segenap kemampuannya dalam bagaimana dia menyandingkan antara pengalamannya serta imajinasi yang ada dalam dirinya. Senyata apapun cerita yang dialami oleh seorang pengarang, tentunya tetap memerlukan taburan imajinasi pengarang itu sendiri agar sebuah cerita menjadi jauh lebih indah, memiliki nilai estetis, dan lebih menarik untuk dinikmati.

Sebuah karya yang baik adalah karya yang mampu memberikan kesan bagi para pembacanya. Karya yang baik juga mampu membuat pembaca menyatu dengan karyanya, menikmati karya, mendapatkan kepuasan dan pencerahan jiwa dari amanat yang tersirat maupun tersurat dalam sebuah karya yang dewasa ini terus berkembang seiring perkembangan zaman dan budaya di Indonesia khususnya.

Sastra merupakan hasil karya imajinasi manusia baik berupa cerpen, novel, atau puisi. Sastra 
merupakan ekspresi penghayatan dan pengalaman batin pengarang terhadap masyarakat dalam situasi dan waktu tertentu. Sastra di dalamnya digambarkan tentang keadaan kehidupan suatu masyarakat, seperti adanya nilai kejadian yang mencerminkan kehidupan suatu masyarakat pada suatu masa, karena sastra merupakan suatu gambaran tentang pengalaman batin manusia yang sepenuhnya dialami sendiri dalam kehidupannya.

Sastra merupakan suatu pencerminan kehidupan masyarakat, setiap karya sastra dapat mengungkapkan jalan cerita yang dialami oleh seseorang (tokoh), juga dapat mengungkapkan aspek-aspek kehidupan manusia dan kemanusiaan yang lebih mendalam (Hidayat, 2017).

Menurut (Saini K.M, 1990) bahwa "Sastra mempunyai hubungan dengan kehidupan, yaitu sebagai pemekat (intensifikator). Dalam karya sastra yang memekatkan, pengalaman kehidupan disaring, dijernihkan, diambil sarinya, dan dikristalkan sehingga pembaca dapat mengambil hikmah dan kekayaan pengalaman itu dengan mudah dan dalam waktu yang singkat.

Dari beberapa karya sastra yang dihasilkan oleh sastrawan, salah satunya adalah Novel. Novel merupakan hasil karya sastra tentang penggambaran kehidupan manusia, baik fiksi atau nonfiktif. Fiksi biasanya si pengarang berimajinasi dalam karyanya. Nonfiksi, pengarang bercerita mengenai dirinya sendiri dengan nama disamarkan atau cerita tentang kehidupan temannya.

Sastra memiliki fungsi bagi pembaca, salah satunya yaitu berguna dan menyenangkan. Berguna untuk masyarakat pembaca, artinya karya sastra yang dibaca memberi efek positif atau manfaat yang baik bagi pembacanya. Menyenangkan artinya selain mengandung pesan-pesan tertentu, sebuah karya sastra juga dapat memberikan rasa gembira, kepuasan batin, juga pemenuhan terhadap kebutuhan spiritualnya.

Sastra memiliki pencerminan dalam kehidupan. Kehidupan manusia dari lahir sampai meninggal tertuang dalam alur kisah dalam karya sastra, baik drama, cerpen, atau novel. Oleh karena itu, terjadilah jembatan berkesinambungan berbagai nilai manusia dan masyarakat. Pikiran dan falsafah terkandung dalam alur cerita karya sastra, di dalamnya membentuk suatu kepribadian kepada kita dengan demikian turut berperan dalam perubahan masyarakat.

Banyak pengalaman hidup yang dikemukakan dalam sebuah karya sastra. Pengarang melalui tulisannya mengenalkan bermacam-macam konflik yang selalu ada dalam masyarakat. Konflik tersebut dimulai dari masalah biasa sampai dengan klimaks, lalu kemudian penyelesaian atau antiklimaks. Oleh karena itu, karya sastra ditulis bukan saja bagi manusia perseorangan dalam memperbaiki watak dan perangainnya, karena dalam watak tokoh ada peran antagonis (jahat), protatonis (baik), dan tritagonis (penengah).

Banyak dari karya sastra bangsa kita timbul setelah melihat keadaan sosial masyarakat dan keadaan kebudayaan yang ada pada saat itu, karyakarya tersebut tentunya akan bersifat realisme. Pengarang dengan kemampuannya merefleksikan apa yang dialaminya di dalam suatu sistem sosial kemasyarakatan akan menceritakan representasi dari pengalamannya tersebut di dalam karyanya. Pengarang itu sendiri akan menceritakan kondisi pada saat itu mulai dengan bahasa yang sulit dimengerti khalayak, sampai bahasa yang ringan. Yang terpenting bagi para sastrawan adalah apa yang akan disampaikan dapat dipahami oleh pembaca tanpa adanya kesalahpahaman maksud antara pengarang dan pembaca itu sendiri.

Sosiologi adalah suatu telaah yang objektif dan ilmiah tentang manusia dalam masyarakat dan tentang sosial dan proses sosial. Sosiologi menelaah bagaimana masyarakat tumbuh berkembang. Dengan mempelajari lembaga-lembaga sosial dan segala masalah perekonomian, keagamaan, politik, dll, kita mendapat gambaran tentang cara manusia menyesuaikan diri dengan lingkungannya, mekanisme masyarakatnya, serta proses pembudayaaannya. Dalam sosiologi terdapat identitas sosial, adalah antara lain, dapat diketahui dari pertanyaan apa dan siapa penutur tersebut, dan bagaimana hubungannya dengan lawan tuturnya. Maka, identitas penutur dapat berupa anggota keluarga (ayah, ibu, kakak, adik, paman, dan sebagainya), dapat berupa teman karib, atasan atau bawahan (di tempat kerja), guru, murid, tetangga, pejabat, orang yang dituakan, dan sebagainya (Chaer, 2004).

Penilaian sosial yang berbeda oleh penutur terhadap bentuk-bentuk perilaku ujaran. Maksudnya, setiap penutur tentunya mempunyai kelas sosial tertentu di dalam masyarakat. Maka, berdasarkan kelas sosialnya, dia mempunyai penilaian tersendiri.

Masalah sosiologi mencakup beberapa hal, antara lain macam-macam gejala kehidupan masyarakat dan sosial yaitu nilai-nilai dan moral. Secara konkret, sosiologi mempelajari kelompokkelompok dalam masyarakat, seperti keluarga, clan (subsuku), suku, dan bangsa. Di dalamnya masyarakat ada semacam lapisan, seperti lapisan penguasa dan lapisan rakyat jelata, atau ada kastakasta yang berjenjang, juga dipelajari dalam sosiologi. Sosiologi mencakup teori yang hanya dalam batas 
tertentu menyangkut nilai-nilai sosial dan moral. Soekanto menjelaskan :

"Nilai-nilai merupakan konsepsi abstrak dalam diri manusia mengenai apa yang baik dan apa yang buruk. Sistem nilai-nilai tersebut tumbuh sebagai hasil dari pengalaman manusia di dalam mengadakan proses interaksi sosial. Pengalaman baik akan menghasilkan nilai positif, sedangkan pengalaman buruk akan menghasilkan nilai negatif, artinya nilai positif seharusnya dianuti, nilai yang negatif sebaiknya selalu dihindari misalnya mencuri, berbohong, melakukan korupsi dan lain-lain." (Soekanto, 1988).

Dari uraian yang dijelaskan oleh Shadily, Sosiologi ilmu yang mempelajari hidup bersama dalam masyarakat, berarti sosiologi berurusan dengan manusia dalam masyarakat sebagai usaha manusia untuk menyesuaikan diri dan usahanya untuk mengubah masyarakat. Begitupun dengan sastra, dapat dianggap sebagai usaha untuk menciptakan kembali dunia sosial yaitu hubungan manusia dengan keluarga, lingkungan, politik, negara, ekonomi, dan sebagainya yang juga menjadi urusan sosiologi.

Hubungan antara masyaraakat dengan kebudayaan sangatlah erat, karena kebudayaan itu sendiri adalah suatu kumpulan manusia atau masyarakat mengadakan sistem nilai yaitu berupa aturan yang menentukan suatu benda atau perbuatan lebih tinggi nilainya. Singkatnya kebudayaan itu dikatakan sebagai cara hidup, yaitu bagaimana masyarakat mengatur hidupnya.

Sosiologi karya sastra yaitu sosiologi yang mempelajari karya sastra. Novel merupakan salah satu karya sastra. Sastra menampilkan gambaran kehidupan, dan kehidupan itu sendiri adalah suatu kenyataan sosial. Dalam hal ini kehidupan mencakup hubungan antara masyarakat dengan individu atau individu dengan individu.

Pendekatan sosiologi karya sastra merupakan suatu pendekatan yang mengungkapkan kehidupan manusia. Persoalan mengenai manusia ditampilkan pengarang melalui karya sastra sehingga terdapat berbagai ragam karya sastra dan berbagai persoalan tentang kehidupan itu sendiri.

Menurut Semi kebudayaan dalam sosiologi karya sastra memiliki tiga unsur :

I. Unsur Sistem Sosial : Sistem sosial ini terdiri dari, sistem kekeluargaan, sistem politik, sistem ekonomi, sistem kepercayaan, sistem pendidikan, dan sistem undangundang. Terdapat struktur dalam setiap sistem yang dikenal sebagai institusi sosial, yaitu cara dengan yang lain dalam jalinan hidup bermasyarakat.
2. Sistem Nilai dan Ide : sistem yang memberi makna kepada kehidupan bermasyarakat, bukan saja terhadap alam sekeliling, bahkan juga terhadap falsafah hidup bermasyarakat itu. Sistem nilai juga menyangkut upaya bagaimana kita menentukan sesuatu lebih berharga dari yang lain, sementara sistem ide merupakan pengetahuan dan kepercayaan yang terdapat dalam sebuah masyarakat.

3. Peralatan Budaya : penciptaan material yang berupa perkakas dan peralatan yang diperlukan untuk menunjang kehidupan." (Semi, 1989).

Sosiologi karya sastra yaitu sosiologi yang mempelajari karya sastra. Novel merupakan salah satu karya sastra. Sastra menampilkan gambaran kehidupan, dan kehidupan itu sendiri adalah suatu kenyataan sosial. Dalam hal ini kehidupan mencakup hubungan antara masyarakat dengan individu atau individu dengan individu.

Berdasarkan uraian di atas penulis akan menguraikan analisis novel Pudarnya Pesona Cleopatra karya Habiburrahman El-Shirazy, mengenai aspek sosiologi karya sastra yang ada dalam novel Pudarnya Pesona Cleopatra karya Habiburrahman El-Shirazy.

Hasil karya sastra seperti novel yang baik akan berisikan nilai-nilai kehidupan yang mampu memperkaya landasan pola perilaku manusia. Untuk memahami isi karya sastra, khususnya yang ada, maka perlu dilakukan dengan pendekatan. Berkaitan dengan aspek sosiologi karya sastra, pendekatan yang dapat digunakan untuk melihat atau menemukan nilai-nilai dan norma-norma yang baik untuk dapat dijadikan sebagai sarana pendidikan adalah pendekatan sosiologi karya sastra.

\section{Metode}

Metode penelitian ini adalah metode deskriptif analisis isi, dengan mendeskripsikan aspek sosiologi karya sastra ada dalam novel Pudarnya Pesona Cleopatra karya Habiburrahman El-Shirazy.

Objek penelitian, aspek sosiologi karya sastra pada novel Pudarnya Pesona Cleopatra karya Habiburrahman El-Shirazy diterbitkan oleh Republika, Jakarta, November 2005, 5 I halaman.

Fokus dalam penelitian ini adalah aspek sosiologi karya sastra novel Pudarnya Pesona Cleopatra karya Habiburrahman El-Shirazy. 


\section{Hasil dan pembahasan}

Hasil dan pembahasan pada penelitian ini membahas aspek-aspek sosiologi karya sastra novel Pudarnya Pesona Cleopatra karya Habiburrahman El-Shirazy.

\section{a. Unsur Sistem Sosial 1) Sistem Politik}

Sistem politik adalah sebagai pola yang tetap dari hubungan-hubungan antar manusia yang melibatkan, sampai dengan tingkat yang berarti, kontrol, pengaruh, kekuasaan, ataupun wewenang. (Haryanto, 1982)

Setelah penulis analisis di dalam novel Pudarnya Pesona Cleopatra karya Habiburrahman El-Shirazy tidak ada sistem politik, karena novel ini novel psikologi Islami pembangun jiwa, jadi tidak ada unsur politiknya.

\section{2) Sistem Kepercayaan}

Sistem kepercayaan adalah pemahaman terhadap segala aspek alam semesta yang dianggap sebagai suatu kebenaran. (Soekanto, I988)

"Dalam pergaulatan jiwa yang sulit berhari-hari, akhirnya aku pasrah. Aku menuruti keinginan ibu. Aku tak mau mengecewakan ibu. Aku ingin menjadi mentari pagi dihatinya, meskipun untuk itu aku harus mengorbankan diriku". (PPC, hlm 3)

Dari petikan di atas, orang tua adalah orang yang harus kita junjung, bahkan nasihatnya harus kita turuti. Kepercayaan apapun apa yang dikatakan oleh orang tua, sebagian orang harus dituruti, bahkan meski harus mengorbankan diri.

"Dimanakah petuah-petuah suci kenabian itu kusimpan?” ( $P P C$, hlm 5)

Bagi umat Islam Nabi Muhammad saw adalah manusia yang harus ditaati, dan jadi panutan. Jika kita mengikuti akhlak Nabi Muhammad saw kita mendapatkan pahala.

"Dihari-hari menjelang akad nikah aku berusaha menumbuhkan bibit-bibit cintaku pada istriku, tetapi usahaku selalu saja sia-sia." (PPC, hlm 5)

Menjelang hari akad nikah aku berusaha menumbuhan bibit cinta kepada Raihana, istrinya, tetapi usahaku selalu saja sia-sia.

"Ibu, durhakalah aku

Jika dalam maumu tak ada mauku

Tapi durhakakah aku, ibu?

Jika dalam diri raihana taka ada cintaku" ( $P P C$, hlm 5)
Patuh terhadap orangtua wajib hukumnya, durhakalah jika kita tidak patuh terhadap orang tua.

"Apa mau dikata, cinta adalah anugerah Tuhan

yang tak bisa dipaksakan, pesta meriah dengan

bunyi empat grup rebana terasa konyol." ( $P P C$, hlm 6)

Dari petikan di atas, Cinta adalah anugerah Tuhan yang tidak bisa kita hindari, semua akan indah jika kita mempunyai cinta.

"Lantunan shalawat nabi terasa menusukmenusuk hati. Inna lillahi wa ilahi rajiun! Perasaan dan nuraniku benar-benar mati." (PPC, hlm 6)

Orang-orang yang apabila ditimpa musibah akan berucap Innalillahi'wa innailaihi rojiun.

"Satu-satunya, harapanku hanyalah berkah dari Tuhan atas baktiku pada ibu yang amat kucintai. Rabbighfir li wa liwalidayya!" ( $P P C$, hlm 6)

Dari petikan di atas, Ridho Allah adalah ridho orang tua. Oleh karena itu, kita harus berbaki kepada orang tua agar Allah memberkahi kita.

"Duhai tuhan mohon ampunan. Aku yang terbiasa membaca ayat-ayat-Nya kenapa bisa itu menebas leher kemanusiaanku. Dan aku pasrah tanpa daya." ( $P P C$, hlm 7)

Melantunkan ayat-ayat Al-Quran harus meresapi makna dan kandungannya. Tetapi pada diri tokoh belum bisa menerima Raihana, di mana kemanusiaan yang selama ini dimaknainya.

"Wiwiting tresno jalaran soko kulino! Artinya, hadirnya cinta sebab sering bersama. Tapi pepatah itu agaknya tidak berlaku untukku." (PPC, hlm 7)

Kepercayaan orang jawa atas petuah itu, cinta hadir karena sering bersama.

"Cinta yang salah kedaden memang sering menciptakan orang-orang gila." ( $P P C, \mathrm{hlm} 8$ )

Menurut pepatah Jawa, cinta yang salah kadeden sering menciptakan orang-orang gila.

"Mas kumohon bukalah hatimu untuk menjadi ruang bagi pengabdianku, bagi menyempurnakan ibadahku di dunia ini." (PPC, hlm II)

Dari petikan di atas, pernikahan merupakan ibadah utama dalam pergaulan masyarakat agama Islam. Sebagai seorang muslim, pernikahan menjadi panutan dalam menjalankan kehidupan sehari-hari, dan ada baiknya kita mengikuti apa yang dicontohkan dan diajarkan oleh Rasulullah. Dan pernikahan merupakan salah satu sunnah dari Rasulullah.

"Seribu doa terpanjatkan agar hatiku terbuka. (PPC, hlm I8) 
Doa adalah permohonan kepada Allah yang disertai kerendahan hati untuk mendapatkan suatu kebaikan dan kemaslahatan yang berada di sisi-Nya.

"Acara pengajian dan aqiqah-an putra ketiga

Yu Fatimah, kakak sulung Raihana, membawa sejarah baru dalan lembaran pernikahan kami." (PPC, hlm 23)

Aqiqah adalah kegiatan syariat Islam, memotong hewan qurban untuk dijadikan pengurbanan atas rasa syukur kepada Allah swt.

"Sejak kecil zaenab tidak pernah tersingkap auratnya. Ayahnya, Pak Kiai Ahmad sangat ketat menjaga akhalak dan moral anak-anaknya, Agung sungguh keliru.” (PPC, hlm 30)

Islam mengajarkan aurat perempuan ada batasannya. Aurat adalah bagian tubuh manusia yang tidak boleh dilihat oleh bukan mahramnya apalagi dipegang. Untuk wanita seluruh tubuh kecuali kedua telapak tangan dan wajah.

"Hanya Allah-lah tempat ia meratap melabuhkan dukanya, dan....... ya Allah, ia setia memanjatkan doa rabithah, doa ikatan cinta dengan tulus dan ikhlas untuk kebaikan suaminya." (PPC, hlm 46)

Allah sebaik-baiknya tempat bersandar. Saat sedih dan suntuk menghampiri. Saat banyak hal yang dicita-citakan dan diinginkan. Saat ada sesuatu yang sangat ditakutkan dan dikhawatirkan. Bersimpuhlah di hadapan Al-Rahman (Dzat Maha Pengasih dan Penyayang).

"Rabbi dengan penuh kesyukuran, hamba bersimpah di hadapan-Mu. Lakal Hamdu Ya Rabb. Telah engkau mulia akan hamba dengan alquran. Kau kuatkan diri hamba dengan cahaya alquran. Kalaulah bukan karena karunia-Mu yang agung ini, niscaya hamba sudah terperosok dalam jurang kenistaan. Ya Rabbi, curanhkan tambahan kesabaran pada diri hamba....." (PPC, hlm 46)

Berdoa salah satu kepercayaan umat Islam atas curahan hati kepada Illahi Rabbi.

"Ya allah, dengan rahmatMu hamba memohon jangan engkau murkai dia karena kelalaiannya. Cukup hamba saja yang menderita. Biarlah hamba saja yang menanggung nestapa. Jangan engkau murkai dia, dia adalah ayah dari janin yang hamba kandung ini. Jangan engkau murkai dia, dengan cinta hamba telah memaafkan segala khilafanya, hamba tetap menyayanginya, ya allah berilah hamba kekuatan untuk setia berbakti dan memuliakanya. Ya allah,Engkau Maha tau bahwa hamba sangat mencintainya karena-Mu. Ya sampaikanlah rasa cinta hamba ini kepadanya dengan cara-Mu yang paling bijaksanna. Tegurlah dia dengan teguran
rahmat-Mu. Ya allah, dengarkanlah doa hamba$\mathrm{Mu}$ ini. Tiada Tuhan yang layak disembah kecuali Engkau. Mahasuci Engkau ya allah,sungguh hamba mengakui hamba termasuk golongan orang-orang yang zhalim. Amin” (PPC, hlm 48)

Raihana memohon doa dan petunjuk kepada Allah SWT. Untuk jangan murkai dia (suami) atas kelalaiannya. Biar hamba saja yang menanggung nestapa. Jangan murkai dia, karena dia adalah ayah yang ada di janin yang dikandung.

Raihana mencurahkan bahwa dia sangat mencintai suaminya, tolong sampaikan rasa cinta Raihana kepada suaminya wahai zat Yang Maha Agung.

"Ibu mertua mengajakku kesebuah gundukan tanah masih baru di kuburkan yang letaknya dipinggir desa. Diatas gundukkan itu ada dua batu nisan. Nama dan hari wafat Raihana tertulis disana." (PPC, hlm 50)

Bagi agama Islam setiap orang yang meninggal, dikafani, disalatkan, dan dikuburkan. Di atas kuburan ada batu Nisan dilengkapi dengan nama dan hari wafat.

\section{3) Sistem Ekonomi}

Sistem ekonomi merupakan suatu kumpulan dari aturan atau kebijakan yang saling berkaitan dalam upaya memenuhi kebutuhan untuk mencapai kemakmuran. Sistem ekonomi ini juga berkaitan dengan hubungan manusia dengan perekonomiannya yang sangat erat hubungannya dengan bagaimana kita mencukupi kebutuhan manusia tersebut. (Kuswardayo, 2002)

"Saya anak tunggal seorang yang cukup kaya dipinggir timur kota Medan. Ayah memiliki sawah dan ladang yang cukup luas dan ibu seorang pedagang kain yang cukup sukses.” (PPC, hlm 34)

Dari petikan di atas, bahwa tokoh saya anak tunggal dari orang yang kaya di Medan. Bisnis ayah dan ibunya sukses. Ayahnya memiliki sawah dan ladang, sementara ibu pedagang kain yang sukses.

"Akhirnya, dengan biaya yang sangat tinggi saya berhasil memperistri Yasmin.” (PPC, hlm 36)

Dari petikan di atas, seorang tokoh (saya) dapat memperistri Yasmin dengan biaya yang sangat tinggi.

"Saya harus mengeluarkan biaya yang sangat mahal. Yasmin menuntut diberi suatu yang lebih dari gadis Mesir yang menikah dengan orang Mesir pada umumnya. Dia minta dibelikan mobil. Perabot rumah yang agak mewah. Musim panas pergi ke Alexandria menginap di hotel yang berbintang dan lain sebagainya." (PPC, hlm 37) 
Tokoh (saya) mengeluarkan banyak harta, untuk memenuhi keinginan Yasmin. Misalkan, Yasmin ingin dibelikan mobil, perabot rumah tangga yang mewah, musim panas pergi ke Alexandria menginap di hotel mewah.

"Saya minta asset yang miliknya di Mesir dijual untuk memulai hidup di Indonesia." ( $P P C$, hlm 37)

Dari petikan di atas, tokoh saya meminta untuk menjual aset, untuk memulai kehidupan di Indonesia.

"Biaya hidup semakin bertambah. Saya minta kepada Yasmin untuk lebih berhemat. Tidak setiap tahun ke Mesir tapi tiga tahun sekali." (PPC, hlm 37)

Tokoh (saya) meminta kepada istrinya Yasmin untuk berhemat, karena biaya hidup semakin bertambah. Ke Mesir tidak setiap tahun sekali, tetapi tiga tahun sekali.

"Bisnis tidak selamanya untung, ada kalanya jatuh. Tapi harus bangun lagi jika ingin eksis.

Setengah tahun yang lalu bisnis yang saya jalani jatuh." ( $P P C$, hlm 38)

Dari petikan di atas, bisnis merupakan aktivitas yang memberikan keuntungan. Tetapi kadang bisnis bisa jatuh dalam arti gulung tikar, jika bisnis tersebut tidak dijalankan dengan benar.

"Kekayaan yang ada tinggal dua. Rumah mewah yang sedang di tempati berikut isinya, dan perhiasan Yasmin." (PPC, hlm 39)

Tokoh saya mengungkapkan, harta yang tadinya melimpah ruah sekarang kekayaan yang ada tinggal dua rumah dan perhiasan Yasmin.

"Saya minta Yasmin menjual perhiasanya yang bernilai ratusan juta untuk modal usaha. Dia tidak mau." (PPC, hlm 39)

Dari kutipan di atas, saya meminta menjual perhiasan istrinya, Yasmin, untuk modal usaha. Tetapi Yasmin tidak mau.

"Ayah ibu mengalah. Mereka menjual rumah dan tanah tempat mereka tinggal dan uangnya seluruhya diberikan kepada saya. Untuk modal.

Mereka berdua tinggal diruko yang kecil dan sempit." ( $P P C$, hlm 40)

Orang tua dari tokoh (saya) mengalah, yang tadinya harta melimpah, skrg semuanya habis. Bahkan orang tua dari tokoh (saya) menjual rumah dan tanah tempat tinggal dan uang seluruhnya diberikan kepada tokoh (saya), untuk modal.

\section{4) Sistem Pendidikan}

Pendidikan sebagai pengalaman belajar yang berlansung dalam segala lingkungan hidup dan sepanjang hidup, baik di sekolah atau di luar sekolah, karena pendidikan merupakan segala situasi yang memengaruhi pertembuhan seseorang sebagai suatu proses pengembangan diri individu dan kepribadian seseorang yang dilaksanakan secara sadar, serta nilainilai penyesuaian diri dengan lingkungan. (Idris, 1992)

"Aku masih bisa mengajar di kampus dengan baik. Masih bisa menjawab pertanyaanpertanyaan mahasiswa dengan baik." ( $P P C$, hlm 8)

Dalam petikan di atas, tokoh (Aku) masih bisa mengajar dengan baik dan menjawab pertanyaan dengan baik, walaupun mungkin sedang ada masalah yang sedang dihadapi.

"Belajarku lima tahun diluar negeri sia-sia." (PPC, hlm 9)

Dari kutipan di atas, belajar lima tahun di luar negeri sia-sia.

"Untuk menghibur diri suatu hari sepulang dari mengajar. Kulihat kaset sinetron berseri Ibnu Hazm yang kubawa dari Mesir." ( $P P C$, hlm I9)

Sepulang mengajar, menghibur diri dengan menonton kaset Sinetron Ibnu Hazm.

"Dan lintasan kehadiran Raihana itu hilang setelah aku berangkat mengajar. Dalam rutinitas harian yang mulai padat, Raihana sudah terlupakan sama sekali. Sampai akhirnya suatu hari dikampus ada barita yang cukup mengagetkan sesama dosen. Ketika aku makan siang bersama pak Hardi da pak Susilo terjadilah perbincangan itu." ( $P P C$, hlm 28)

Lintasan Raihana hilang begitu saja saat mengajar. Dengan segala rutinitas harian padat, Raihana sudah terlupakan.

"Apalagi ketika aku mandapatkan tugas di Universitas untuk mengikuti pelatihan peningkatan mutu dosen mata kuliah bahasa Arab selama sepuluh hari yang akan diadakan oleh Depag dipuncak." (PPC, hlm 3I)

Salah satu kewajiban dosen mengikuti pelatihan yang diselenggarakan oleh Depag dalam meningkatkan mutu mata kuliah bahasa Arab.

"Tapi dalam diri saya, mulai muncul penyelesaian setiap kali saya melihat temanteman alumni Mesir yang hidup tenang dan damai dengan istrinya. Bisa mengamalkan ilmu dan berdakwah dengan baik. Tidak dikejarkejar dengan kepentingan istri yang melangit.” (PPC, hlm 3I)

Tokoh (aku) mulai iri dengan temannya sesama alumni Mesir yang bisa hidup tenang dan damai dengan istrinya. Bisa mengamalkan ilmu dan berdakwah. 


\section{b. Unsur Sistem Nilai dan Sistem Ide}

Sistem nilai merupakan sistem memberi makna kehidupan masyarakat, bukan saja terhadap alam sekeliling, bahkan juga terhadap falsafah hidup masyarakat itu.

"dan percayalah pada ibu, Anakku. Ibu selalu memilihkan yang terbaik untukmu. Ibu tahu persis garis keturunan Raihana. Ibu tahu persis kesalehan kedua orang tuanya," tambahanya untuk menyakinkan diriku. (PPC, hlm 2)

Ridho orangtua adalah ridho Allah swt. Seorang ibu yang memilihkan anaknya untuk menikah dengan pilihan ibunya. Pilihan orangtua pasti yang terbaik terhadap anaknya.

"Mbak Raihana itu orangnya baik kok, kak. Dia ramah halus budi, sarjana pendidikan, penyabar, berjilbab dan hafal Al-Quran lagi. Pokoknya cocok deh buat kakak," komentar adikku,si Aida tentang calon istriku. ( $P P C$, hlm 2)

Dari petikan di atas, memberikan beberapa argumen positif tentang Raihana, agar tokoh (aku) menerimanya dengan ikhlas.

"Tapi seleraku lain. Entah mengapa. Apakah mungkin karena aku telah begitu hanyut citra gadis-gadis Mesir Titisan Cleopatra yang tinggi semampai? Yang berwajah putih jelita dengan hidung melengkung indah, mata bulat bening khas Arab, dan bibir merah halus menawan." (PPC, hlm 4)

Dari kutipan di atas, selera setiap orang berbeda-beda, tokoh (aku) memang begitu istimewa, seleranya titisan gadis Mesir, Cleopatra yang tingginya semampai. Berwajah putih jelita dengan hidung melengkung indah, mata bulat bening khas Arab, dan bibir merah halus menawan.

"Aura pesona kecantikan gadis-gadis Mesir Titisan Cleopatra sedimikian kuat mengakar dalam otak, perasaan dan hatiku, sedimikian kuat menjajahkan cita- cita dan mimpiku." (PPC, hlm 5)

Dari petikan di atas, pesona kecantikan gadis Mesir sedemikian mengakar dalam otak dan pikiran.

"Senym manis Raihana tak juga menembus batinku. Suaranya yang lembut tetap saja terasa hambar. Wajahnya yang teduh tetap saja terasa asing bagiku.” (PPC, hlm 7)

Senyuman manis Raihana tidak membuat hatiku luluh, tidak menembus batinku. Suara lembut Raihana tetap terasa hambar di telinga. Wajahnya yang ayu dan teduh tetap terasa asing bagiku.

"Tapi ia adalah perempuan Jawa sejati yang selalu berusaha menahan segala badai dengan kesabaran. Perempuan Jawa yang selalu mengalah dengan keadaan. Yang salalu menormorsatukan suami dan menomorduakan dirinya sediri." (PPC, hlm I0)

Dari petikan di atas, bahwa perempuan Jawa berbeda dengan perempuan lain di luar Jawa. Perempuan Jawa selalu mengerti dengan keadaan baik senang atau sedih, gembira atau muram. Perempuan Jawa sangat menghormati suaminya, apapun yang dibilang suami selagi itu positif pasti akan dituruti oleh istri.

"Kenapa mas memanggilku"mbak"? aku 'kan istri mas. Apakah mas tidak mencintaiku?" tanyanya dengan gurat sedih tampak diwajahnya." (PPC, hlm IO)

Dari petikan di atas, pernikahan hal yang sakral. Tetapi Aku memanggil Raihana istrinya, mbak. Kutipan di atas menggambarkan bahwa Raihana tidak senang dipangggil mbak, oleh suaminya, Aku.

"Kuminta asal jangan satu hal: yaitu menceraikan aku! Itu adalah neraka bagiku. Lebih baik aku mati daripada mas menceraikanku." (PPC, hlm II)

Dalam Islam perceraian itu hal yang tidak diinginkan, Rasulallah pun tidak senang dengan perceraian. Raihana begitu pasrah meminta pengharapan kepada tokoh (aku/suami), bahkan meminta untuk tidak menceraikannya.

"Wajah yang cukup manis tapi tidak semanis dan seindah gadis-gadis lembah sungai Nil." (PPC, hlm I4)

Banyak orang menganggap Raihana manis, tetapi tidak bagi $\mathrm{Aku}$, gadis-gadis lembah sungai Nil yang manis.

"Tapi cinta adalah selera. Dan selera orang berbeda-beda. Dan aku selalu menolak jika orang mengatakan gadis Mesir banyak yang gembrot. Aku justru melihat jika ada delapan gadis Mesir maka yang cantik ada enam belas. Karena banyangannya juga cantik. Aku mungkin terlalu memuja keelokan gadis Mesir." (PPC, hlm I9)

Dari petikan di atas, tokoh (aku) menilai cinta itu sesuai selera individu. Dan selera orang berbedabeda. Tokoh (aku) sangat mengagumi gadis Mesir, walaupun gadis Mesir banyak orang yang bilang gembrot.

"Aku mungkin terlalu memuja keelokan gadis Mesir. Itulah selera. Selera adalah rasa suka yang muncul begitu saja dalam jiwa dan terkadang susah dipahami.” (PPC, hlm I9)

Penilaian akan kecantikan seorang wanita tergantung selera laki-laki. Dari kutipan di atas tokoh Aku sangat memuja gadis Mesir. Hal itu karena selera. Selera adalah rasa suka yang muncul begitu saja dalam jiwa dan terkadang sulit dipahami. 
"Perempuan berjilbab yang satu ini memang luar biasa, ia tetap sabar mencurahkan bakti meskipun aku dingin dan acuh tak acuh padanya selama ini." (PPC, hlm 22)

Dari petikan di atas, perempuan berjilbab memang luar biasa, walaupun (tokoh aku) dingin dan acuh padanya, ia tetap sabar mencurahkan bakti.

"Selamat datang pasangan paling ideal dalam keluarga!" sambut yu imah disambut tepuk bahagia mertua dan ibundaku sendiri serta kerabat yang lain wajah raihana cerah.” (PPC, hlm 23)

Yu Imah menyambut Aku dan Raihana dengan tepuk bahagia, 'selamat datang pasangan paling ideal dalam keluarga'. Wajah Raihana menjadi cerah atas sambutan tersebut.

"Dia lebih menuruti hawa nafsunya dari pada nuraninya. Padahal di zaman edan seperti ini mencari perempuan salehah lebih sulit dari pada mencari perempuan cantik. "terang pak Susilo." (PPC, hlm 3I)

Pak Susilo menilai zaman edan seperti ini mencari perempuan salehah lebih sulit daripada mencari perempuan cantik.

"Dan kau sungguh termasuk orang yang beruntung. Kata teman-teman dosen. Kau mendapatkan isteri yang sangat ideal. Cantik, pintar karena dia terbaik dikampusnya penurut, kelihatanya sangat setia karena dia kalau memandang pasti menunduk, tidak pernah memandang kedepan melihat lelaki lain, dan hafal alquran. Kau sungguh beruntung," Kata Pak Hardi. (PPC, hlm 3I)

Dari petikan di atas, beruntunglah bila mendapatkan seorang istri yang cantik, pintar, setia, tidak pernah menatap laki-laki lain selain suami, dan hafal al-Qur'an.

"Sungguh menyesal aku menikah denganmu orang Indonesia ! sungguh menyesal! Aku minta, kau ceraikan aku sekarang juga ! aku tidak bisa hidup bahagia kecuali dengan lelaki Mesir." (PPC, hlm 4I)

Perempuan Mesir menilai menikah dengan orang Indonesia adalah suatu hal yang menyesal.

"Saya telah memilih isteri yang salah. Saya menyesal telah menomorsatukan kecantikan. Istri yang cantik tapi berperangan buruk adalah saksikan yang paling menyakitkan bagi seorang suami." ( $P P C$, hlm 43)

Dari petikan di atas, mengatakan bahwa saya telah memilih isteri yang salah, karena menomorsatukan kecantikan bukan kesalehan.

"Yang paling tepat pemuda Indonesia adalah menikah dengan gadis Indonesia yang paling mengerti watak dan sifat pemuda Indonesia." (PPC, hlm 43)

Pada kutipan di atas, mengatakan bahwa pemuda Indonesia lebih tepat menikah dengan gadis Indonesia, karena watak dan sifat sama.

"Ya cinta itu datang dalam keharuanku. Dalam kaharuanku terasa ada hawa sejuk turun dari langit dan merasuk dalam jiwaku, seketika itu, pesona kecantikan Cleopatra memudar; berganti cahaya cinta Raihana yang terbang di hati." (PPC, hlm 48)

Dari petikan di atas, terkadang cinta itu datang berawl dari keharuan, pesona kecantikan Cleopatra memudar, berganti cahaya cinta Raihan yang menghinggap di hati.

"Ketika aku sedang merasakan cinta yang membara pada Raihana, ia telah tiada. Ketika aku ingin menebus semua dosa yang keperbuat padanya, ia telah meninggalkan aku." ( $P P C$, hlm 50)

Ketika cinta itu hadir, Raihana telah tiada. Ketika tokoh (aku) ingin menebus semua dosa yang diperbuat kepada Raihana, dia telah meninggalkan aku.

Sistem ide, pengetahuan yang dimiliki manusia atas kepercayaan yang diaplikasi ke dalam masyarakat.

"Dengan panjang lebar ibu menjelaskan, sebenarnya sejak ada didalam kandungan aku telah dijodohkan dengan Raihana yang tak pernah kukenal itu. kok bisa-bisanya ibunya berbuat begitu. Pikiran orang dulu terkadang memang aneh." (PPC, hlm 2)

Dari kutipan di atas, ibu menjelaskan panjang lebar mengenai ide yang pernah diucapkan, bahwa sejak dalam kandungangan telah dijodohkan dengan Raihana. Wanita yang belum pernah dikenal sebelumnya.

"Aku ingin merasakan seperti apa indahnya mencintai seorang isteri!" jerit batinku menggedor-gedor jiwa." (PPC, hlm 7)

Dari petikan di atas bahwa, aku ingin mencintai seorang isteri, jerit batinku.

"Aku tidak mau membenci atau muak pada siapa pun juga, apalagi pada isteri sendiri yang seharusnya kusayang dan kucinta." ( $P P C$, hlm 8)

Dari petikan di atas, aku tidak mau membenci pada siapapun juga, apalagi pada isteri sendiri yang seharusnya aku cintai dan sayangi.

"Mas masuk angin. Biasanya kalau masuk angin diobati pakai apa mas, pakai balsam, minyak kayu putih atau pakiai jamu?"tanya Raihana sambil menuntunku kekamar." (PPC, hlm I3) 
Raihana bertanya kepada suaminya, mas saat masuk angin, biasanya diobati pakai apa mas? Minyak kayu putih atau jamu.

"Aku memperhatikan wajah Raihana, aku jadi kembali sedih. Wajah yang cukup manis tapi tidak semanis dan seindah gadis-gadis lembah sungai Nil.” ( $P P C$, hlm I4)

Dari petikan di atas, aku memperhatikan wajah Raihana yang manis, tetapi bagiku gadis-gading lembah sungai Nil lah yang manis dan indah nan elok.

"Pak Soemardaji juga mengingatkan bahwa perempuan bule tidak cocok untuk pemuda Indonesia.” (PPC, hlm 30)

Pak Soemardaji mengingatkan perempuan bule tidak cocok untuk pemuda Indonesia.

\section{c. Peralatan Budaya}

Peralatan budaya, yaitu pencipta material yang berupa perkakas dan peralatan yang diperlukan untuk menunjang kehidupan.

"Dalam balutan jilbab sutra putih wajah gadis Mesir itu bersinar-sinar, seperti permata Zabarjad yang bersih, indah berkilau tertempa sinar purnama." (PPC, hlm 4)

Dari petikan di atas, balutan jilbab gadis Mesir seperti permata Zabarjad yang bersih, indah berkilau tertempa sinar purnama.

"Terkadang bibit cinta yang kuharapkan itu malah menjelma menjadi tiang gantungan yang mencekam.” (PPC, hlm 5)

Dari petikan di atas, bibit cinta yang diharapkan ternyata tidak sesuai dengan kenyataan, malah menjelma menjadi tiang gantungan.

"Aku datang seumpama tawanan yang digiring ketiang gantungan.” (PPC, hlm 6)

Dari petikan di atas, Aku datang bagai tawanan yang digiring ketiang gantungan.

\section{Simpulan}

Novel Pudarnya Pesona Cleopatra karya Habiburrahman El-Shirazy memiliki tiga aspek sosiologi karya sastra yaitu sebagai berikut. Unsur sistem sosial yang meliputi sistem politik sebanyak 0 poin, sistem kepercayaan sebanyak I8 poin, sistem ekonomi sebanyak 9 poin, dan sistem pendidikan sebanyak 6 poin. Dari hasil analisis unsur sistem sosial meliputi sistem politik, sistem kepercayaan, sistem ekonomi, dan sistem pendidikan. Terlihat jelas bahwa lebih menitik beratkan sistem kepercayaan. Dominasi sistem kepercayaan terlihat dari tokoh Aku yang percaya bahwa patuh kepada orang tua wajib hukumnya. Kepercayaan itu ditandai dengan kutipan "Dalam pergaulatan jiwa yang sulit berhari-hari, akhirnya aku pasrah. Aku menuruti keinginan ibu. Aku tak mau mengecewakan ibu. Aku ingin menjadi mentari pagi dihatinya, meskipun untuk itu aku harus mengorbankan diriku”. Kemudian sistem kepercayaan yang dianalisis akhir halaman "Ibu mertua mengajakku kesebuah gundukan tanah masih baru di kuburkan yang letaknya dipinggir desa. Di atas gundukkan itu ada dua batu nisan. Nama dan hari wafat Raihana tertulis disana.

(2) Sistem nilai sebanyak 20 poin dan sistem ide sebanyak 6 poin. Hasil analisis, sistem nilai lebih menonjol dari sistem ide. Sistem nilai merupakan sistem memberi makna kepada kehidupan masyarakat, bukan saja terhadap alam sekeliling, bahkan juga terhadap falsafah hidup masyarakat itu. Dominasi tersebut dapat dilihat dari tokoh Aku yang patuh sekali kepada ibunya. Baginya patuh terhadap ibu nilai yang sangat berharga walaupun di sisi lain batinnya tersiksa, karena menikah dengan wanita yang tidak dicintainya. Dan tokoh Ibu yang menjodohkan anaknya 'Aku' dengan Raihana, Ibu sudah mempunyai penilaian tersendiri terhadap Raihana, lihat dari kutipan berikut "dan percayalah pada ibu, Anakku. Ibu selalu memilihkan yang terbaik untukmu. Ibu tahu persis garis keturunan Raihana. Ibu tahu persis kesalehan kedua orang tuanya," tambahanya untuk menyakinkan diriku." Analisis pada penyelesian Ketika aku sedang merasakan cinta yang membara pada Raihana, ia telah tiada. Ketika aku ingin menebus semua dosa yang keperbuat padanya, ia telah meninggalkan aku.

Peralatan Budaya sebanyak 3 poin. Di novel ini hanya ada 3 poin mengenai peralatan budaya, karena novel ini mengisahkan tentang percintaan. "Dalam balutan jilbab sutra putih wajah gadis Mesir itu bersinar-sinar, seperti permata Zabarjad yang bersih, indah berkilau tertempa sinar purnama."

\section{Persantunan}

Artikel ini tidak luput dari bantuan berbagai pihak, terutama Universitas Indraprasta PGRI yang berkontribusi memfasilitasi berbagai hal. Sebagai penulis, saya mengucapkan terima kasih kepada dewan redaksi Bahastra Universitas Ahmad Dahlan yang telah mewadahi hasil penelitian, kajian bahasa dan sastra Indonesia.

\section{Daftar Pustaka}

Chaer, Abdul. Leonie Agustin. (2004). Sosiolinguistik. Jakarta : Rineka Cipta

Haryanto. (1982). Sistem Politik Sebagai Pengantar. Yogyakarta : Liberti 
Hidayat, Ryan. (2017). “Aspek Sosiologi Sastra dalam Novel Menggapai Matahari Karya Demawan Wibisono". Jurnal Retorika. Volume I0, Agustus

Idris, Zahara. (1992). Pengantar Pendidikan I. Jakarta : PT Grasindo

Kuswardoyo. Pembelajaran Ilmu Pengetahuan Sosial Terpadu dan Kontekstual. Jakarta : Mediatama

Saini K.M. (1990). Protes Sosial dalam Sastra. Bandung : Angkasa
Semi, M. Atar. (1989). Kritik Sastra. Bandung : Angkasa (1998). Anatomi Sastra. Padang : Angkasa Raya

Shadily, Hasan. (1989). Sosiologi untuk Masyarakat. Jakarta : Bina Aksara

Soekanto, Soerjono. (1988). Memperkenalkan Sosiologi. Jakarta : Rajawali Pers

(1990). Sosiologi Suatu Pengantar. Jakarta : PT Raja Grafindo Persada 